\title{
Overview of Stress and Stress Management
}

\author{
Eredoro Christian O.*, Egbochuku Obiageli O. \\ Department of Health, Safety and Environmental Education, University of Benin, Benin City, Nigeria
}

*Corresponding Author: Eredoro Christian O, Department of Health, Safety and Environmental Education, University of Benin, Benin City, Nigeria.Email: eredorochristian@gmail.com

\begin{abstract}
Stress is an unavoidable component of our everyday life. This paper is aimed at instilling the right knowledge that will enable every individual to understand as well as to recognise various sources of stress in their lives and to equip them with the right tools to deal with stress. An attempt is made to explain in details the concept of stress, the way by which they can enter our lives, their types based on psychological perspectives and its lifespan. Two coping method were examined which are the problem-focused coping and the emotional focused coping.
\end{abstract}

Finally different stress management techniques which are very effective in dealing with stress were considered.

Keywords

Stress: This is the experience of tension.

Stressors: These are the sources of stress i.e. situations and events that cause stress.

Coping: This is the change we imbibe in our behaviour as we attempt to deal with stress.

Stress Management Techniques: These are practicesble activities or exercise that helps to eliminate or reduce stress.

\section{INTRODUCTION}

We live in a dynamic world whose environment has, and will continually pose demands (central to our survival) on us. Meeting these demands require some form of behavioral readjustments or reaction from us i.e. psychological and emotional responses. The body's natural way of responding to these demands of our ever changing world is referred to as stress.

Stress is an unwanted characteristics of life (Adeyemo \& Ogunyemi, 2005) as well as an evolutionary necessity for our survival (Ballesteros \& Whitlock, 2009) which has been implicated by numerous researches in the etiology of most health and behavioural problems either as a risk or precipitating factor, and perhaps the most pernicious among all the factors contributing to poor health and early death (Marcola, 2016). It is also thought to influence a wide range of physiological processes and disease state, with existing evidence supporting it as a risk factor in depression, cardiovascular disease, HIV/AID's, delayed wound healing, upper respiratory infection, autoimmune disease and total mortality (Cohen \& Janicki-Devert, 2012). It can make one more likely to catch less serious illness like cold as well as a contributor to obesity, alcoholism, drug addiction, cigarette use and other harmful behaviors (Mountain State Centers for Independent Living).

This is not to state that stress is bad in all its ramifications as some are, and will continue to be helpful in our modern life since it motivates us to accomplish tasks or make changes (Ballesteros \& Whitlock, 2009), improve performance, reach goals and allowing us to learn and grow (Cohen $\&$ Helquist, 2012). Therefore, since stress is an inevitable element of our lives, learning about stress and how it can be effectively managed is paramount if we must live happy and healthy.

\section{WHAT IS STRESS}

The term 'stress' is a highly subjective phenomenon that is very difficult to define as it has been used by people to describe a wide range of things. It refers to the experience of being subjected to physical, mental or emotional strain in response to real or imagine stimuli (Lehloo, 2008). It could also be understood as a state of tension experienced by individuals facing extraordinary demands, constraints or opportunities. Such state of tension or strain experienced could be physiological or psychological.

Physiological stress is experienced when there is a disturbance in the body's state of equilibrium thereby resulting in physiological responses. 
Stress can therefore be regarded as a physiological response to events and situations that causes an upset in the homeostasis of the body. Psychological stress experience is directly affected by the way one evaluate events and situations, as a result everyone does not experience the same event as stressful, as what may be stressful to one may not be to another and vice versa. According to Sarafino (2012), stress arises when individuals perceives a discrepancy between the physical or psychological demands of a situation and the resources of his or her biological, psychological or social system. It also occurs when an individual perceives that environmental demands tax or exceed his or her adaptive capacity (Cohen, Kessler \& Gordan, 1995).

While there is no universally acceptable definition for stress, modern definitions of stress all recognise that it is a personal experience caused by pressure or demands on an individual, and impact upon the individuals ability to cope or rather, his or her perception of that ability (Blaug, Kenyo \& lekhi, 2007).

\section{STRESSORS: SOURCES OF STRESS}

A stressor is any event, situation, experience or environmental stimulus that is perceived as a threat or a challenge that cause stress to an individual. In other word, a stressor is the source or cause of stress. Stress originates from many sources which can be either external or internal, they could be environmental, social, psychological, or even from significant life events. Understanding these sources can help in coping adequately, reducing and even relieving stress from our lives.

\subsection{External Sources of Stress}

These are sources outside us and they include the following:

- Physical environment

- Job

- Pollution

- Noise

- Micro organism (bacteria, viruses, fungi etc.)

- Toxins

- Poor working conditions e.g. poor air circulation and lack of privacy

- Home

- Injury etc.

\subsection{Internal Sources of Stress}

These are sources inside us. They include the following:
- Fear e.g. fear of flying, public speaking etc.

- Attitude

- Feeling of anger

- Worrying about future events e.g. waiting for medical test result, examination result or job restructuring

- Imagination

- Anticipation

- Memory

- Thoughts

- Nutritional status

- Overall health and fitness level

- Presence of illness or infection

- Unrealistic or perfectionist expectation

- Habitual behaviors such as:

- Over scheduling

- Failing to be assertive/unassertive

- Failing to plan ahead

- Failing to set and maintain healthy boundaries

- Procrastination etc.

Stressor could also be categorized into the following:

1. Environmental Stressor: This refer to the aspects of our environment and surrounding that cause us stress. Examples of environmental stressor include weather, noise, overcrowding, pollution, traffic, unsafe and substandard housing etc.

2. Social Stressors: This relates to the social roles we occupy. Meeting the demands of the social roles we occupy could cause us a great deal of stress. The stress they cause usually results from interacting, socializing and communicating with other human beings. Some examples of social roles that cause stress are being an employee, spouse, parent, caregiver, teacher etc. Social stress also include financial problems, disagreements, demands for our time and attention, lost of love one, co-parenting, divorce, job interviews, presentations etc.

3. Physiological Stressor: Situations and circumstances affecting our body as well as the body's normal processes can be a source of stress. Example include body change during puberty, rapid growth of adolescent, ageing, giving birth, illness, menopause, poor nutrition, accident, sleep disturbance etc. 
4. Psychological Stressor: The mental and emotional characteristics of an individual can be a source of stress. Such characteristics include our mindset, how we think and rationalize as well as how we interprets and perceive situations. Some life events and situations are stress provoking, but it is our thought that determines whether they will be a problem.

5. Significant Event Stressor: These sources of stress revolves around significant events and critical incidents in our life. Some significant event leads to positive stress e.g. school graduation, wedding, having a child, winning a sporting event among others. There are also significant events that cause negative stress, they are often referred to as critical life incidents e.g. serious accidents, physical or sexual assault etc.

It is important to note that stressor are inherently neutral. Meaning that a single stressor can cause either positive amd negative stress depending on one's interpretation/perception of the stressor as a threat and the judgement of his or her ability to cope with it.

\section{TYPES OF STRESS}

Stress can be categorized from different perspectives. From psychological perspective there is good stress and bad stress. The term 'stress' has often be used to describe negative situation, and has made many people to believe that all stress is bad. This is not true as there are some stress that are very good.

\subsection{Good Stress-Eustress}

Good stress also known as eustress or positive stress is a positive cognitive response that an individual possess towards a stressor. It is the type of stress that instead of being harmful and detrimental to the individual, it becomes beneficial by helping the individual to improve his or her life. Eustress is fun, exciting and energizing in that it motivates one to complete a given task or achieve a set goal. Some benefits of eustress include increase creativity, increase productivity, improve self esteem, and health benefit like stimulation of immune system for optimum operation, boosting of adrenaline and epinephrine secretion which can help with everything from improved agility, moving faster, thinking clearly, and improved brain function among others. It can also lead to feeling of satisfaction, fulfilment, accomplishment, wellbeing and wholeness. According to Hansen (2015), eustress occurs during moments in an individual's life when a degree of motivation is required to overcome potentially difficult obstacles. He further explained that the body gains huge benefits from regular instances of good stress as the individual feels a brief period of elevated worry which is then quickly transformed into relaxation once the given task is completed. However, it is important to note that positive stress depletes the body's reserves just as much as negative stress does, and overexposing oneself to positive stressor without effectively managing the stress can transform positive stress into negative stress thereby inducing exhaustion (Lehloo, 2008).

Important factors that helps in experiencing a stressful situation positively are:

- A believe system and mindset of hope, expectation and a positive attitude to life.

- Believe in oneself and self - ability to tackle the stressor.

- A perception that one has power and control over the stressful situation.

- Expectation of the best of oneself.

- Expectation of reward.

\section{Characteristics of Good Stress}

- It motivates and focuses energy.

- It is short-term.

- It is perceived to be within ones coping ability.

- It feels exciting and fun.

- It improves performance.

Examples of Good Stress

- Engaging in a challenge.

- Engaging in sports.

- A desired physical activity such as weight training.

- Receiving a promotion.

- Meeting a work deadline.

- Managing the daily, repeating stress of a job.

- Preparing for an examination.

- Taking education courses or leaning a new hobby.

- Watching a suspenseful or scary movie.

- The excitement of falling in love.

- Gambling.

- Labor and delivery.

- Planning for wedding.

- Planning for a vacation etc. 


\subsection{Bad Stress-Distress}

Bad stress also known as distress or negative stress is the direct opposite of good stress. It is the type of stress that is harmful and detrimental to us. Distress could also be seen as a maladaptive response to stressful situations, in other word, it results from ones inability to cope with the demands placed on him/her by stressor. Distress leads to poor decision making and some of it manifestation includes anxiety, sorrow, pain and even the symptoms of mental illness. It could also lead to manifestation of physiological or behavioral symptoms. Physiological symptoms may include increase in blood pressure, rapid breathing, and generalized tension among others, while behavioral symptoms may include aggression, overreaction, drinking, smoking as well as other negative coping mechanisms. Other symptoms may also include soliloquy, hallucination, delusions, recklessness, decrease pleasure in sexual activities, obsessive thought or compulsions, belief that others can hear one's thought or that one's thought is not his own, anger management problems etc.

\section{Characteristics of Bad Stress}

Distress are know to have the following Characteristics

- It causes anxiety or concern.

- It can be short or long term.

- Feels unpleasant.

- Decrease performance.

- It is perceived to be beyond ones coping ability.

- Can lead to mental or physical problems.

Examples of Bad Stress

- The death of a partner or family member.

- Hospitalization. (oneself or family member).

- Injury or illness. (oneself or family member).

- Unemployment.

- Excessive job demands.

- Job insecurity.

- Conflict in interpersonal relationship.

- Conflict with team mate or supervisor.

- Unproductive and time consuming meeting.

- Child's problem at school.

- Money problems.

- Legal problems.

- Sleep problems.
- Being abused or neglected.

- Separation from a spouse or a committed relationship partner.

- Being a victim of bully etc.

Stress can also be categorized from the perspective of it's timespan i.e how they come and how long they last, if it come suddenly or if it has lingered since the body respond to stressor differently depending on wether the stressor is new or short-termed or whether it has remained for a long time. The categories are:

- Acute stress.

- Episodic acute stress.

- Chronic stress.

- Post traumatic stress (PTS)

\subsection{Acute Stress}

This is the most common form of stress. It manifests from recent events or from the expectation of future events. Acute stress may feel exciting and exhilarating but too much of it do more bad than good. It is short termed and as such does not have the time to do any damage like long termed stress will do. It is highly treatable and manageable. Symptoms of acute stress may include anger, anxiety, irritation, depression, headache, muscle tension, stomach ache, constipation, increase in blood pressure, rapid heart beat, chest pain, back pain etc.

\subsection{Episodic Acute Stress}

This is the type that affect people that suffers frequent incidents of acute stress. The lives of people who are victims of this type of stress are so disordered and filled with chaos and crisis, at such are perpetually in the grips of acute stress. Such people are always too busy, taking too much on themself and not being able to organise themself. As far as they are concern they see nothing wrong with the way they conduct their life, blaming their woes on others and external events. Symptoms of episodic acute stress may include headache, migraine, chest pain, hypertension, heart disease among others. Episodic acute stress can be addressed with certain lifestyle changes, however professional help may be employed before it escalates to any chronic problems.

\subsection{Chronic Stress}

This is the type of stress that arises from long lasting events and circumstances that are beyond one's control. It is long termed, debilitating and can be seen in people suffering from adverse situations such as disdained career, endless 
poverty, unhappy marriage, dysfunctional family etc. with no way out. In other word, it is the wearing stress that people feel when they don't see a way of escape out of the problem and demands that continually make their life miserable. Some chronic stress stems from traumatic and/or childhood experiences that becomes internalized and remain forever painful and present. This class of stress can kill through suicide, violence, heart attack, stroke and perhaps cancer (America Psychological Association) Chronic stress is difficult to treat, however professional and medical assistance such as counseling and targeted behavioral therapy can help.

\subsection{Post-Traumatic Stress Disorder (PTSD)}

This type of stress is associated with frightening and distressing events such as traumatic experience from one's childhood, war, poverty, sexual abuse etc. Sufferers of this stress can have strong feeling of guilt, emotional numbness, constant worry, depression and can even retrieve traumatic event through nightmares and flashbacks (Dr Kelly \& Associates, 2014).

\section{Stress MANAGement AND COPING}

Stress management is a predetermined action taking process aimed at controlling a persons level of stress. It involves taking charge of one's thought, emotions and lifestyle as a whole including the way one deals with his or her personal problems for the purpose of improving functionality. Stress management encompasses the use of a wide variety of techniques and psychotherapies that adequately equip one to cope effectively with stress.

Coping according to Lazarus and Folkman (1984) is defined as a constantly changing Cognitive and behavioral effort to manage specific external and internal demand that are appraised as taxing or exceeding the resource of the person. It is also defined by Campas et al (as cited by skinner et al, 2007) as a conscious and volitional effort to regulate emotions, cognition, behavior, physiology, and the environment in response to stressful events or circumstances. In other word, coping as a process seeks to help one master, minimise or tolerate stress, whereas stress management enhances coping.

People choose different coping strategies or mechanisms to deal with stress, some are positive or adaptive while some others are negative or maladaptive and thus ineffective. Their choices often times are Influenced to a great extent by their personality, gender, social environment and even the nature of the stressor that is involved. Lazarus and Folkman (1984) grouped coping into two types which are problem focused coping and emotional focused coping.

\subsection{Problem Focused Coping}

This kind of coping also referred to as active coping is one that ais at resolving the stressful situation or event. It involves modifying or eliminating the fundamental source of the stress. Problem focused coping helps individuals in taking control of the stress, seek relevant information or needed assistance in tackling the situation or removing oneself from the stressful situation. Problem focused coping is the best in coping with stress in that it provides a long-term solution by dealing with the root cause of the stress. However, it is not possible to use problem focused coping in all situations e.g for the death of a loved one, using problem focused coping will be ineffective for the bereaved. At such, emotional focused coping becomes the most appropriate and effective. This therefore implies that the effectiveness of problem focused coping depends on the changeability of the stressor: whether or not the stressor can be changed.

\subsection{Emoticon Focused Coping}

This kind which is a passive form of coping is directed towards managing the negative distressing emotions caused by stressful situations or events i. e one alters his or her emotions in order to tolerate or eliminate the stress. The strategies of emotion focused coping when employed helps one to feel better but does not proffer a solution to the source of the distress thereby providing a short term relieve. The use of emoticon focused coping is best and most effective when it involves a problematic situation that are out of one's control (e.g terminal illness and sudden death) since problem focused coping will not do any good. Some examples of emotion focused coping strategies include listening to music, meditation, journaling, distraction, avoidance, cognitive reappraisal, alcohol and drug use, seeking social support, taking a hot bath e.t.c.

\section{Stress Management Techniques}

Stress management techniques when practiced on a regular basics help to bring about relaxation response in the body. Relaxation response is a physical state of deep rest as described by Benson (1975) that changes the physical and emotional response to stress, which also is an opposite of the fight or flight response. Stress management techniques are not only beneficial to people who are already experiencing the symptoms of stress 
but also to stress free people who employ them as proactive measures to combat stress. Common among these techniques are explained below:

\subsection{Exercise}

Physical activity is one major stress management technique which has been found to contribute to effective coping (Kim \& Mckenzie, 2014). Our encounter with stressful situations often times increase the body's level of stress hormones such as adrenaline and cortisol, these hormones are metabolized during physical activity thereby restoring the body and mind to a calmer and relaxed state. Exercise warms and relaxes cold tight muscles and tissues which contribute to stress feelings. it develops and maintain a healthy body which directly reduces stress and susceptibility as well as increasing blood flow to the brain, stimulating nervous system, releasing hormones and chemicals such as beta-endorphins which has a positive effect on how we feel, and improving quality of sleep. It also releases tense muscles and tight connective tissues which are often responsible for stress feelings and symptoms. Exercise also plays a distracting function drawing one's attention from the stressor especially when it involves a competitive activity as it makes one to push himself further than he will normally do. Examples of exercises include brisk walking, jogging, swimming, rowing, biking, dan ing e.t.c. Since any exercise can increase fitness and reduce stress, it is important to choose an activity that one enjoy rather than dread.

\subsection{Progressive Muscle Relaxation (PMR)}

This is another technique for stress management and reduction of overall body tension. It involves alternatively tensing and relaxing specific muscle group in a sequential and systematic pattern to combat stress. Such muscle group could include those of the arms, legs, chest, abdomen, neck, back e.t.c. When using this technique, one should be extremely cautious so as not to cause harm to self while tensing muscles. Also one should endeavour to seek for professional counsel from physicians before engaging this technique when a medical condition such as muscle or bone problem exist which can hinder physical activity. The mental component of PMR requires that one focus on the distinction between the feeling of the tension and the relaxation (Varvogil \& Darviri, 2011). With regular practice, PMR helps one to recognise what tension as well as complete relaxation feels like in different part of the body and as result one is able to spot and counteract the first signs of muscle tension that accompanies stress (Klinic Community Health Centre, 2010).

\subsection{Diaphragmatic Breathing}

Diaphragmatic breathing also known as deep breathing, abdominal breathing, belly breathing, or paced respiration. is another technique that involves the manipulation of breathing movement by contracting the diaphragm to induce relaxation. According to the University of Texas Counseling and Mental Health Center, "Diaphragmatic breathing allows one to take normal breaths while maximizing the amount of oxygen that goes into the bloodstream. It is a way of interrupting the 'Fight or Flight' response and triggering the body's normal relaxation response.". Diaphragmatic breathing also stimulates the parasympathetic nervous system which induce a state of calmness thereby releasing tension from the body improving both physical and mental wellness. Stress often times comes along with a change in breathing pattern, for instance anxiety is characterized by small and shallow breath using the shoulder to inhale and exhale instead of the diaphragm hereby creating an imbalance in the gases (oxygen and carbon dioxide) in the body. This kind of small shallow breath can lengthen the feeling of anxiety as well as aggravating the physical symptoms of stress. It is important to note that other than curbing stress diaphragmatic breathing also help in the improvement of pulmonary function, cardiorespiratory fitness, posture, respiratory muscle length, and respiratory muscle strength.

\subsection{Visualization/Guided Imagery}

Visualization is a stress management technique which can be thought of as mental vocation which comprises of the arousal of perceptual experiences across the sensory modalities i.e the use of one's innate power of imagination such as the Imagination of smell, hearing, touch, taste and movement to induce a state of relaxation in the body in the same manner that one's thoughts which causes anger and anxiety can induce tension and stress in the body. Such Imaginations could involve picturing oneself in a tranquil, serene and relaxing setting or place with all its details that is particularly appealing and soothing to one. It could be a real setting that one has actually visited in the past or a total product of one's imagination. Examples of such setting could be beach, park, forest, tourist centre etc.

\subsection{Meditation}

Meditation is another potent stress management technique that can induce a deep state of relaxation and tranquil mind. It helps to quiet the mind, master or even eliminate completely the negative thought patterns which are often the 
fundamental cause of stress. It can also enhance one's resilience level as well as make one less reactive to stress. This result in an enhanced physical and emotional wellbeing and an overall improvement of health.

\subsection{Social Support}

Social support is another potent antidote to stress. It is simply referred to as the functions performed to an individual by significant other to help cope with adversity. Such significant others include family members, friends, church and even coworkers.

\section{CONCLUSION}

For us to enjoy life to its fullness in health and vitality, we must take total responsibility in identifying the various sources of stress in our individual lives and choose for ourselves as we deem worthy the best strategy or technique that will enable us cope and manage effectively the stress of our lives.

\section{REFERENCES}

[1] Adeyemo, D. A. \& Ogunyemi B. (2005) Emotional intelligence and self-efficacy as predictors of occupational stress among academic staff in Nigeria University. Retrieved July 10, 2016 from http://www. leadingtoday. org/we lead in learning/da05.htm.

[2] Balesteros, D. \& Whitlock, J.L. (2009). Coping: Stress management strategies. The Fact Sheet Series, Cornel Research Program on Self-Injury and Recovery. Cornel University. Ithaca, NY

[3] Billings, A. G., \& Moos, R. H. (1985) "Life stressor and social resources affect post treatment outcomes among depressed patients." Journal of Abnormal Psychology, 94, 140-153.

[4] Blaug, R. Kenyon, A. \& Lekhi, R. (2007) Stress at work: A report prepared for The Work Foundation's Principal Partners. London: The work foundation.

[5] Boundless (2016) Coping with stress. Retrieved July 10, 2016 from https://www.boundless.com/ psychology/textbooks/boundless-psychologytextbook/stress-and-health-psychology-17/ coping-with-and-managing-stress-89/copingwith-stress-337-12872/

[6] Cohen, S. \& Janicki-Deverts, D. (2012) Who's Stressed? Distributions of Psychological Stress in the United States in Probability Samples from 1983, 2006, and 20091, Journal of Applied Social Psychology, 42(6), 1320-1334. doi: 10.1111/j.1559-1816.2012.00900.xx
[7] Cohen, B. \& Helquis, M. (2012) E-Portfolio: Coping with stress Retrieved July 10, 2016 from https://bethcohen.wordpresscom/generalstudies/english-2010/revised-drafts/copingwith-stress/

[8] Cohen, S., Kessler, R., \& Gordon, U. (1995) Strategies for measuring stress in studies of psychiatric and physical disorder. In S Cohen, R Kessler, \& U Gordon (Eds.), Measuring Stress: A Guide for Health and Social Scientists. New York, NY: Oxford University Press.

[9] Dr Kelly \& Associates (2014) Different kinds of stress-acute stress, episodic acute stress, chronic stress and post-traumatic stress Retrieved July 10, 2016 from http://drkellys.co.uk/dealing-with -stress/

[10] Hansen, F. (2015) Bad stress vs good stress. Retrieved from http://adrenalfatiguesolution. com/bad-stress-vs-good-stress/

[11] Klinic Community Health Centre, (2010) Stress and stress management. Canada: author.

[12] Lazarus, R. \& Folkman, S. (1984) Stress, appraisal, and coping. New york: Springer Publishing Company.

[13] Lehloo, I. (2008) Adero Education Foundation: Positive Stress, Negative Stress. Retrieved July 10, 2016 from https://aderoeducation.word press.com/2012/05/30/positive-stress-negativestress/

[14] Mercola, J. (2016) How stress affects your body, and simple techniques to reduce stress and develop greater resilience Retrieved July 10, 2016 from http://articles.mercola.com/sites/ articles/archive/ 2016/04/10/how-stress-affectsbody.aspx

[15] Sarafino, E. P. (2012). Health Psychology: Biopsychosocial Interactions. 7th Ed. Asia: Wiley.

[16] Skinner, E. A. \& Zimmer-Gembeck, M. J. (2007) The development of coping. Annu. Rev. Psychol. 2007. 58:119-44. doi: 10.1146/ annurev.psych.58.110405.085705

[17] Varvogli, L. \& Darviri, C. (2011) Stress management techniques: evidence-based procedures that reduce stress and promote health. Health science Journal, pp:74-89 EISSN:1791-809X

[18] Stress management and reduction Retrieved 28th October 2016 from https://www.cmhc. utexas. edu/stress recess/Level_ Two/breathing. html

Citation: Eredoro Christian O., Egbochuku Obiageli O., Overview of Stress and Stress Management. ARC Journal of Nursing and Healthcare. 2019; 5(2):12-18. doi: dx.doi.org/ 10.20431/2455-4324.0502002.

Copyright: (C) 2019 Authors. This is an open-access article distributed under the terms of the Creative Commons Attribution License, which permits unrestricted use, distribution, and reproduction in any medium, provided the original author and source are credited. 